\title{
Tibial nerve block: evaluation of a novel midleg approach in 241 patients
}

\author{
[Le bloc du nerf tibial : évaluation d'une nouvelle approche chez 241 patients]
}

Pierre Larrabure MD, Pierre Pandin MD, Nathalie Vancutsem MD, Arlette Vandesteene MD PhD

Purpose: Several techniques of tibial nerve (TN) block have been described but require mobilization of the patient. We describe a new landmark, along the internal tibial shaft edge at the midleg level, that allows to block the TN and to insert a catheter with the patient lying supine.

Methods: 24I ASA physical status I to III awake, supine patients were studied prospectively. Cutaneous projections of the internal tibial condyle and the internal malleolus were marked and the needle was inserted $45^{\circ}$ cephalad in an antero-posterior plane, midway on the line between those two points, I cm posterior to the tibial shaft's internal edge. The catheter was introduced in the peri-nervous space using nerve stimulation $(<0.5 \mathrm{~mA})$ on both the Tuohy needle and catheter. Ten millilitres of $2 \%$ lidocaine were injected through the catheter. Cutaneous and dermatomal sensory blockade were assessed using cold and pinprick tests while motor block was assessed using a modified Bromage scale. Satisfaction and analgesia scores were noted after surgery for $48 \mathrm{hr}$. Adverse events were recorded.

Results: The TN was always blocked, matching the distal L5 cutaneous nerve supply. Blood reflux was present in five patients (needle or catheter). No additional adverse events were noted. During the initial postoperative $48 \mathrm{hr}, 0.2 \%$ ropivacaine was infused through the catheter $\left(5 \mathrm{~mL} \cdot \mathrm{hr}^{-1}\right)$ which always provided effective pain relief.

Conclusion: The midleg technique of TN anesthesia and catheter insertion allows patients to remain in the supine position and results in a high rate of homogeneous anesthesia, a low incidence of side effects and effective continuous analgesia.

Objectif : Plusieurs techniques ont été décrites mais nécessitent de mobiliser le patient. Ce nouvel abord permet de bloquer le nerf tibial et d'insérer un cathéter sans bouger le patient.

Méthode : Le nerf tibial a été repéré chez 24I patients ASA I à III en décubitus dorsal en utilisant une stimulation nerveuse à la fois sur l'aiguille de Tuohy et sur le cathéter $(<0,5 \mathrm{~mA})$. L'aiguille était insérée à $45^{\circ}$ vers le haut dans un plan sagittal passant par le milieu entre les sommets respectifs du condyle tibial interne et la malléole interne, juste $\mathrm{I} \mathrm{cm}$ en arrière du rebord interne de la diaphyse tibiale. Dix millilitres de lidocaïne $2 \%$ ont été injectés par le cathéter. Le bloc sensitif dans les territoires nerveux et dans les dermatomes correspondants a été évalué tandis qu'un score de Bromage modifié a permis d'évaluer le bloc moteur. En postopératoire, les scores de satisfaction et analgésiques ont été enregistrés pendant $48 \mathrm{~h}$.

Résultats : Le nerf tibial était toujours bloqué de même que le territoire cutané correspondant à L5. Aucune complication autre que le reflux de sang par l'aiguille ou le cathéter n'a été notée. Durant les 48 $h$ postopératoires, de la ropivacaïne $0,2 \%$ était perfusée dans le cathéter à $5 \mathrm{~mL} \cdot h^{-1}$ et a permis un contrôle efficace de la douleur chez tous les patients.

Conclusion : La technique peut être réalisée facilement sans bouger le patient, permet l'insertion d'un cathéter, un bloc anesthésique homogène, peu de complications et une analgésie postopératoire satisfaisante.

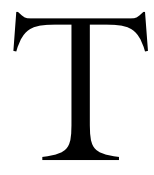

HE tibial nerve (TN) block is now well accepted for the provision of anesthesia or postoperative analgesia for forefoot surgery in adult patients. ${ }^{1-3}$ Several approaches have been described either proximally in the popliteal region $^{4-9}$ or at the ankle ${ }^{2,3}$ but are associated with an incomplete block. A novel antero-internal landmark for TN block was developed at the midleg level to combine firstly, ease of performance in a supine patient, secondly, a high enough approach to block the whole $\mathrm{TN}$, and thirdly, to allow insertion of a catheter for postoperative analgesia. This new stimulation guided approach to the $\mathrm{TN}$ was evaluated

From the Department of Anesthesiology, Erasmus Hospital, Free University of Brussels, Brussels, Belgium.

Address correspondence to: Dr. Pierre C. Pandin, Department of Anesthesiology and Intensive Care, Erasmus Hospital, Lennik Drive 808, B-1070 Brussels, Belgium. Phone: +32 255539 19; Fax: +32 255543 63; E-mail: ppandin@ulb.ac.be

Department and Institution attribution of the work: Department of Anesthesiology and Intensive Care, Erasmus Hospital, Brussels, Belgium. Accepted for publication March 9, 2004.

Revision accepted December 10, 2004. 
prospectively regarding sensory and motor blockade and adverse events. We focus on the technical feasibility of the block, of catheter insertion, and postoperative pain relief.

\section{Material and methods}

After approval of our Ethics Committee, TN anesthesia was proposed to informed patients scheduled for foot surgery (mainly arthroplasty or complex osteotomy) during a two-year period (October 2001 to September 2003).

Each patient was premedicated with $i m$ midazolam $0.1 \mathrm{mg} \cdot \mathrm{kg}^{-1}$ and was further sedated, if needed, before the regional anesthetic procedure with iv sufentanil 2 $\mu \mathrm{g}$ and midazolam $2 \mathrm{mg}$. Landmarks for the TN location and catheter insertion were marked as follows: firstly, the cutaneous projections of the internal tibial condyle and the internal malleolus were identified; secondly, a line between those two-points was marked; we identified a point midway on this line, $1 \mathrm{~cm}$ posterior to the tibial shaft's internal edge (Figure 1). With the patient lying supine, a $50-\mathrm{mm}$ long $\mathrm{HDC}^{\mathrm{TM}}$ (HDC ${ }^{\text {TM }}$ Inc., Milpitas, CA, USA) Tuohy needle, connected to an HNS Stimuplex ${ }^{\mathrm{TM}}$ (BBraun ${ }^{\mathrm{TM}}$ Melsungen AG, Germany) stimulator (current intensity of 0.5 $\mathrm{mA}$, decreased to $0.3 \mathrm{~mA}$ to refine location; frequency and duration of the stimulus of $1 \mathrm{~Hz}$ and $100 \mu \mathrm{sec}$ respectively), was inserted $45^{\circ}$ cephalad in an anteroposterior plane to locate the $\mathrm{TN}$ behind the internal edge of the tibial shaft (Figure 2) until we observed plantar flexions of the first toe. The midleg level was chosen to approach the TN, for two main reasons. Firstly, below the knee and above the midleg using our insertion method, the TN must be encountered prior to the posterior tibial artery (PTA) decreasing the risk of vascular puncture (Figure 2 ) because the TN is more internal and anterior than the PTA. This anatomical situation is inversed below the midleg level. Secondly, the TN is the most superficial at the midleg level. After TN location, a 20-gauge $\mathrm{HDC}^{\mathrm{TM}}$ polyethylene stimulation catheter was inserted through the Tuohy needle, using the same stimulation settings. The length of inserted catheter corresponding to the best quality of muscular twitches was recorded. Finally, the catheter was fixed to the skin using a specific Epi-Fix ${ }^{\mathrm{TM}}$ (Maersk Medical ${ }^{\mathrm{TM}}$ Stonehouse, England, UK) device. After a l-mL negative test dose ( $1 \%$ lidocaine with $1 / 200,000$ epinephrine), $10 \mathrm{~mL}$ of $2 \%$ lidocaine were injected through the catheter. The catheter was left in place 48 hr postoperatively.

Anesthesia and motor block were evaluated just before surgical incision: cutaneous sensory blockade

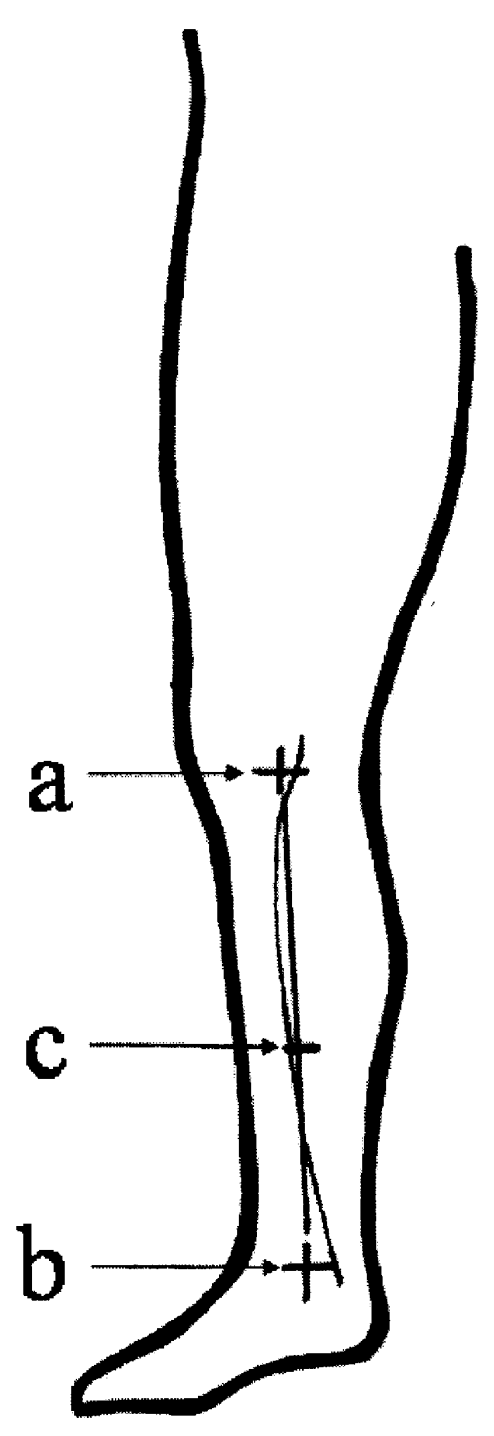

FIGURE 1 Landmarks on the internal face of the leg for the midleg approach to the tibial

a) tibial internal condyle; b) internal malleolus; c) insertion point midway between points a and $\mathrm{b}$, approximatively $\mathrm{l} \mathrm{cm}$ posterior to the internal edge of the tibial shaft. The curved line corresponds to the cutaneous projection of the internal edge of the tibia.

using cold and pinprick tests in the tibial cutaneous nerve territories; dermatomal blockade using cold and pinprick tests in the L4 and L5 cutaneous dermatomes to appraise segmental block; motor block using Bromage's ${ }^{10}$ modified scale specially adapted to the TN (from Bromage 1 - corresponding to the full capacity for plantar flexion of the first toe - to Bromage 4 - corresponding to a total inability to flex the first toe). 


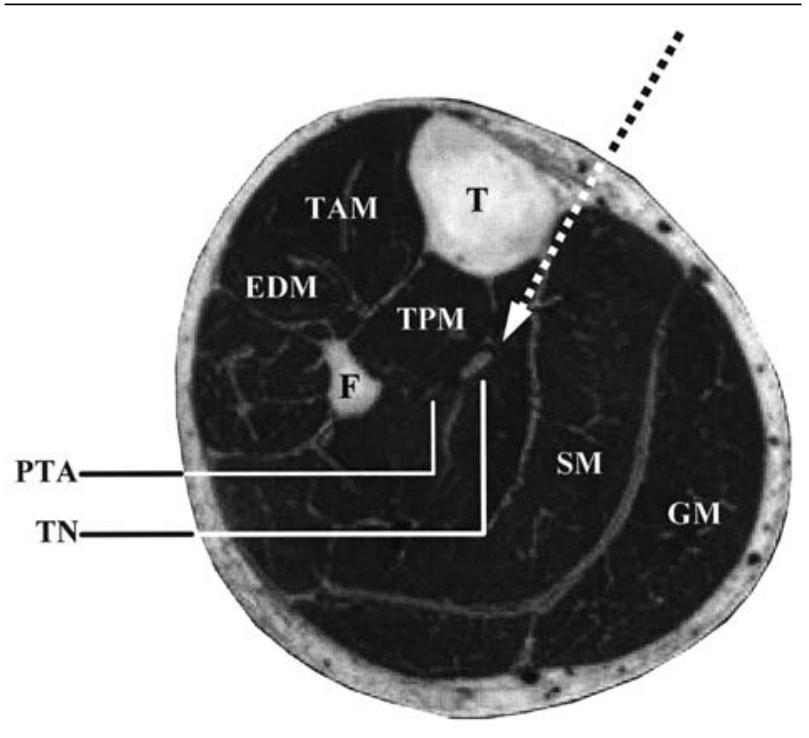

FIGURE 2 Midleg cross section

Tibial nerve (TN); posterior tibial artery $(\mathrm{PTA})$; tibia $(\mathrm{T})$; fibula (F); extensor digitorum muscle (EDM); tibial anterior muscle (TAM); tibial posterior muscle (TPM); soleus muscle (SM); gastrocnemius muscle medial head (GM). The dotted line represents the needle insertion pathway just posterior to the tibial shaft.

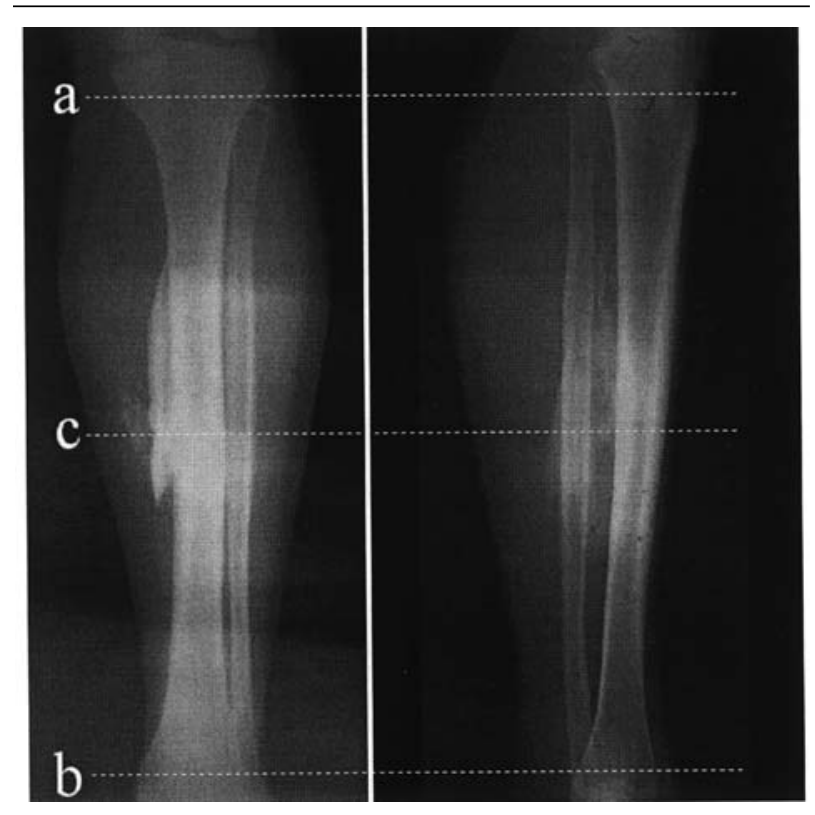

FIGURE 3 Postero-anterior (left) and lateral (right) radiographs of the left leg showing the distribution of radio-opaque dye within the perinervous adipose space through the catheter in a $71-\mathrm{kg}$ patient a) level of the tibial internal condyle; b) level of the internal malleolus; c) insertion of the needle and the catheter. Note that the anesthetic solution diffused not only cephalad around the tibial nerve but also caudad and medially.

The TN was always located but, in five patients, blood reflux was noted through the needle $(n=4)$ or through the catheter $(n=1)$ prior to local anesthetic injection. Consequently, the needle or the catheter was withdrawn and the procedure abandoned. In the remaining 236 patients, the $\mathrm{TN}$ was located after one attempt in 178 patients $(74 \%)$, two attempts in 56 patients $(23 \%)$ and three attempts in seven patients $(3 \%)$. Mean time for performance of the complete procedure was $5.2 \mathrm{~min}(4.2-7 \mathrm{~min})$. The mean length of catheter inserted was $1.7 \mathrm{~cm}$ (range $1-3 \mathrm{~cm}$ ).

An $x$-ray of the leg (Figure 3 ) was taken in a female patient operated for hallux valgus. It illustrates the distribution of the radio-opaque dye $(4 \mathrm{~mL}$ of iohexol $240 \mathrm{mg} \cdot \mathrm{mL}^{-1}$ added to $10 \mathrm{~mL}$ of the anesthetic) within the perinervous adipose space. The anesthetic solution diffused approximately $6 \mathrm{~cm}$ cephalad and $2 \mathrm{~cm}$ caudad to the tip of the catheter.

The effectiveness (sensory and motor block) of the block is summarized in the Table.

Adapted to the individual context, 187 (79.2\%) patients received postural SA and $49(20.8 \%)$ general anesthesia. was $3.7 \mathrm{~cm}$ (range $3-5 \mathrm{~cm}$ ). The mean surgical duration was $85 \mathrm{~min}$ (range from 65-150 $\mathrm{min}$ ). 
TABLE Sensory efficacy, motor block in the tibial nerve distribution and adverse events in 236 patients

\begin{tabular}{lll}
\hline Sensory block & Effective & Percentage \\
\hline Posterior tibial nerve & 236 & 100 \\
L4 & 217 & 92 \\
L5 & 236 & 100 \\
Motor block (modified Bromage > 2) & Presence & Percentage \\
Hallux plantar flexion & 226 & 96 \\
Hallux dorsal flexion & 197 & 83 \\
Adverse events & Presence & Percentage \\
Paresthesia & & \\
$\quad$ On needle advancement & 12 & 5 \\
$\quad$ On catheter insertion & 5 & 2 \\
$\quad$ During anesthetic injection & 2 & 0.8 \\
$\quad$ through the catheter & & \\
Catheter occlusion & 6 & 2.5 \\
Catheter withdrawal before 48 hr & 5 & 2 \\
Catheter disconnexion & 5 & 0.4 \\
Pump failure & 1 & \\
\hline
\end{tabular}

At the end of surgery, pain control was considered optimal in every patient since none requested additional analgesia after being asked specifically. A $0.2 \%$ ropivacaine infusion was programmed for $48 \mathrm{hr}$ at 5 $\mathrm{mL} \cdot \mathrm{hr}^{-1}$ using the Pain Management Provider ${ }^{\mathrm{TM}}$ pump (Abbott Diagnostics $^{\mathrm{TM}}$, North Chicago, IL, USA) in 163 patients $(69 \%)$ or LV5 Infusor ${ }^{\mathrm{TM}}$ pump (Baxter Healthcare $^{\mathrm{TM}}$ Corporation, Deerfield, IL, USA) in 73 patients (31\%). Postoperative infusion lasted $42.8 \mathrm{hr}$ (range 27-48 hr). One hundred eighty seven patients $(79 \%)$ received the complete infusion. The infusion was stopped prematurely in $17(7.9 \%)$ patients because of technical problems (Table) and in 32 (14\%) for patient convenience (patient leaving hospital...). The mean satisfaction score (on a five-point scale) was 4.6 (range $3-5$ ) and the VAS pain score (on a tenpoint scale) was 2.1 (range $0-5$ ).

After the postanesthesia care unit stay (mean of 86 min, range 61-128), supplemental analgesics were not prescribed systematically but only when the VAS score was more than 5 on two successive assessments. Thirty eight patients (16.1\%) received iv pro-paracetamol (30 $\left.\mathrm{mg} \cdot \mathrm{kg}^{-1} \cdot \mathrm{hr}^{-6}\right)$ while 12 of them $(5 \%)$ needed additional $i m$ piritramide $\left(0.25 \mathrm{mg} \cdot \mathrm{kg}^{-1} \cdot \mathrm{hr}^{-6}\right)$ at least once $(n=$ $10)$ and twice in two other patients. Oral tramadol hydrochloride $\left(50 \mathrm{mg} \cdot \mathrm{hr}^{-6}\right)$ was given to 21 patients $(8.1 \%)$ during at least $24 \mathrm{hr}(n=11)$ and always stopped at $48 \mathrm{hr}$.

Finally, no hemodynamic instability (arterial hyperor hypotension) or systemic toxicity was noted after the injection of the anesthetic mixture. No long-term neurological complication has been reported in the series of patients.

\section{Discussion}

Different TN block techniques previously described at the knee level, ${ }^{4-9}$ are recognized as effective for both anesthesia and analgesia when tourniquet time remains below $45 \mathrm{~min}$. Nevertheless, the present tendency is to focus on more peripheral approaches to limit anesthesia as much as possible to the surgical zone in an attempt to decrease the amount of anesthetic mixture infused and the risk of systemic toxicity. We decided to develop the midleg approach when numerous patients complained of the discomfort of the catheter and its pad in the popliteal fossa and because a more distal approach at the ankle could result in a significantly higher occurrence of incomplete TN block. This simplified approach, resulting in an easy to manage catheter is used more and more frequently for ambulatory surgery, ${ }^{11-14}$ allowing an earlier and more comfortable return of the patient at home. Our results demonstrate that the midleg approach is a suitable landmark to both locate the nerve and insert a catheter for postoperative analgesia, remote from the surgical area. Moreover, in our practice, compared to an ankle block, the risk of vascular puncture remains low even if further studies will be necessary to substantiate this claim. The technique is well accepted by the patients, with a low occurrence of pain or other problems during its performance. The low incidence of complications, the high rate of success, the efficiency and the acceptance by patients of the catheter during the postoperative period have led us to change our practice and to perform this technique systematically for this particularly painful surgery. Finally, comparisons with other studies, mainly those involving the sciatic popliteal technique, remain difficult because of the major differences between a multinerve proximal approach ${ }^{4-9}$ and this distal approach blocking only one nerve, specially dedicated to surgery of the first and the second toes. Nevertheless, the midleg approach seems to be an excellent compromise for this particular surgical indication.

\section{Conclusion}

Even if TN anesthesia using the approach described must be completed by spinal or general anesthesia to perform surgery, the postoperative analgesia provided after hallux surgery is useful in daily practice. The advantages of the supine position to perform the block and catheter insertion, the ease of location and of block performance must be emphasized.

\section{References}

1 Mansour NY. Compartment block for foot surgery. A new approach to tibial nerve and common peroneal nerve block. Reg Anesth 1995; 20: 95-9. 
2 Levecque JP, Borne M, Saïssy JM. Analgesia with continuous lateral posterior tibial nerve block (Letter). Reg Anesth Pain Med 1999; 24: 191-2.

3 Colgrove RC. Posterior tibial nerve block. Foot Ankle Int $2001 ; 22$ : 839-40.

4 Avellanal $M$, Ojea R, Peláez M. New approach to tibial nerve by infrapopliteal posterior block (Letter). Reg Anesth 1996; 21: 601-2.

5 Lee TH, Wapner KL, Hecht PJ, Hunt PJ. Regional anesthesia in foot and ankle surgery. Reg Anesth 1996; 19: 577-80.

6 Bareither DJ, Genau JM, Massaro JC. Variation in the division of the tibial nerve: application to nerve blocks. J Foot Surg 1990; 29: 581-3.

7 Singelyn FJ, Aye F, Gouverneur JM.Continuous popliteal sciatic nerve block: an original technique to provide postoperative analgesia after foot surgery. Anesth Analg 1997; 84: 383-6.

8 Singelyn FJ, Gouverneur JM, Gribomont BF. Popliteal sciatic nerve block aided by a nerve stimulator: a reliable technique for foot and ankle surgery. Reg Anesth 1991; 16: 278-81.

9 Rorie DK, Byer DE, Nelson DO, Sittipong R, Johnson $K A$. Assessment of block of the sciatic nerve in the popliteal fossa. Anesth Analg 1980; 59: 371-6.

10 Bromage PR. Epidural Analgesia. Philadelphia: W.B. Saunders; 1978.

11 Rawal N. Patient-controlled regional analgesia (PCRA). Acta Anaesthesiol Belg 1999; 50: 221-5.

12 Rawal N. Analgesia for day-case surgery. Br J Anaesth 2001; 87: 73-87.

13 Rawal N, Allvin R, Axelsson K, et al. Patient-controlled regional analgesia (PCRA) at home. Controlled comparison between bupivacaine and ropivacaine brachial plexus analgesia. Anesthesiology 2002; 96: 1290-6.

14 Capdevilla X, Macaire P, Aknin P, Dadure C, Bernard $N$, Lopez S. Patient-controlled perineural analgesia after ambulatory orthopedic surgery: a comparison of electronic versus elastomeric pumps. Anesth Analg 2003; 96: 414-7. 